\title{
Modelling of Supercapacitors Based on Simplified Equivalent Circuit
}

\author{
Mustafa Ergin ŞAHIN, Frede BLAABJERG, and Ariya SANGWONGWANICH
}

\begin{abstract}
The need for energy storage devices especially in renewable energy applications has increased the use of supercapacitors. Accordingly, several supercapacitor models have been proposed in previous researches. Nevertheless, most of them require an intensive test to obtain the model parameters. These may not be suitable for an initial simulation study, where a simple model based on the datasheet is required to evaluate the system performance before building the hardware prototype. A simplified electrical circuit model for a supercapacitor (SC) based on the voltage-current equation is proposed in this paper to address this issue. This model doesn't need an intensive test for accuracy. The structural simplicity and decent modelling accuracy make the equivalent electrical circuit model very suitable for power electronic applications and real-time energy management simulations. The parameters of the proposed model can be obtained from the datasheets value with a minimum test requirement. The experimental method to provide the parameters of the supercapacitor equivalent circuit is described. Based on the proposed method, the supercapacitor model is built in Matlab/ Simulink, and the characteristics of equivalent series resistance (ESR) measurement and cycle life are compared with datasheets. The simulation results have verified that the proposed model can be applied to simulate the behaviour of the supercapacitor in most energy and power applications for a short time of energy storage. A supercapacitor test circuit is given to test the charge and discharge of supercapacitor modules. The experimental results are suitable for simulation results.
\end{abstract}

Index Terms-Energy storage systems, Matlab/Simulink, Supercapacitors, Supercapacitor modelling.

\section{INTRODUCTION}

$\mathrm{T}$ HERE is a strong demand to reduce the use of fossil fuel and move toward more sustainable energy sources. Accordingly, several efforts have been made to increase the

Manuscript received February 20, 2020; revised June 9, 2020; accepted September 7, 2020. Date of publication March 30, 2021; date of current version March 19, 2021. This work was supported by the Scientific \& Technological Research Council of Turkey (TUBITAK), 2219 postdoctoral research program with a 1059B191700997 application number. This paper is expanded and reviewed from CYSENI 2019 conference presentation.

M. E. Şahin is with the Department of Electrical and Electronics Engineering, Recep Tayyip Erdoğan University, 53100 Rize, Turkey (e-mail: musta faerginsahin@yahoo.com).

F. Blaabjerg and A. Sangwongwanich are with the Department of Energy Technology, Aalborg University, Pontoppidantstraede, 9220 Aalborg East, Denmark (e-mails: fbl@et.aau.dk; ars@et.aau.dk).

Digital Object Identifier 10.24295/CPSSTPEA.2021.00003 penetration level of Renewable Energy Sources (RES) such as photovoltaics and wind turbines [1]. Nevertheless, the intermittency nature of the power production from RES have risen a concern regarding the grid-integration. Energy storage systems are one of the promising solutions to ensure high power quality and stability of the electrical network.

Traditional energy storage devices such as batteries have some limitations as slow charging and limited lifetime. Some other storage technologies, such as mechanical, electrochemical, and electromagnetic, which store the energy in another form, are more expensive and complexes [2]. The fluctuation in the power production of renewable energy sources raises some requirements for the stability of the energy network. The need for instantaneous energy storage devices increases the use of SCs as an alternating storage device, especially in renewable energy applications and electrical vehicles [47], [48]. By employing the SCs, it is possible to smooth out an exact power fluctuation in the renewable energy systems. On the other side, energy storage systems play a significant role in a diverse range of industrial applications [2], [3].

For instance, the increased installation of grid-connected photovoltaic (PV) systems and building integrated PV systems have made rapid advances around the world over the last years. Photovoltaic panels are intermittent sustainable energy sources whose power generation capability varies with the environmental conditions. Thus, energy storage such as SCs can be used to smooth out the power fluctuation due to its high power density [4].

In general, rechargeable batteries and SCs have a similar chemical structure and work process to store and convert through diffusion and migration of ions. However, the SCs present some advantages which will be useful for the storage systems. An SC is a double-layer electrochemical capacitor that can store thousands of times more energy than a typical capacitor. Moreover, they have almost negligible losses and long lifespan [5]. They can process a large number of charge and discharge cycles compared to only a few thousand cycles for lead-acid batteries and can supply much higher currents than batteries [6], [7].

It is possible to find some primary studies in the literature where the chemical, mathematical and electrical characteristics and the dynamic structure of SCs were simulated and investigated [8]-[15]. Also, a simple electrical model of SCs has been designed to describe the behavior of SCs as a function of frequency, voltage, and temperature [16]. However, the 
simplified model is inadequate to demonstrate the SCs dynamics under different operating conditions. On the other hand, the structural simplicity and decent modelling accuracy make the equivalent electrical circuit model designed by Zubieta and Faranda for simulations very suitable for power electronic applications and real-time energy management simulations [22], [23]. The SCs module simulation was based on two branches' electrical circuit model, which included the module structure and its mathematical equation simulation in the previous studies [5], [15], [16]. An experimental method has been discussed in the literature used to determine some of the SC equivalent circuit parameters [15], [17]. Therefore, a simplified SC module model to be used in real-time simulations and to adjust and modified for some parameters is required.

In this paper, the chemical structure of SCs, physical and electrical characteristics, working principles, advantages, and drawbacks are investigated in detail. The chemical, mathematical and electrical and the other developed models in the literature are investigated. Using the equivalent circuit model of the SCs, which is suitable for power electronic practics the mathematical equation of SCs was derived. The procedure to obtain of SCs coefficients experimentally is given. Using this equation and coefficients of the SCs the Matlab/ Simulink model was simulated, and the characteristics of ESR measurement and cycle life are simulated and compared with data sheets for different supercapacitors. Also, charge and discharge characteristics of SCs for different values were simulated to compare the power and energy density of SCs different values. A supercapacitor test circuit is given to test the charge and discharge of SC and modules.

\section{Overview of Supercapacitors Technology}

In this section, an overview of SCs technology including the chemical structure, the physical and electrical characteristics will be discussed in detail. The performance comparison of SCs with the other energy storage technologies will also be provided.

\section{A. Chemical Structure}

A typical SC is shown in Fig. 1(a) where the chemical structure is illustrated in Fig. 1(b) [19], [20]. The capacity of the SCs, which are also called ultra-capacitors or double-layer capacitors, can reach more than a thousand Farads, although the voltage value is only $2.7 \mathrm{~V}$ in most products.

Unlike the ceramic or electrolytic capacitors, SCs do not have dielectric material between positive and negative electrodes. Instead of an electrolyte which has positive ions and negative ions is filled between the two electrodes, it uses the electrical double layer (EDL) that is formed at the interface of the solid electrode and liquid electrolyte. A typical $\mathrm{SC}$ is composed of solid electrodes and liquid electrolytes which including electrolyte salt, and a separator to prevent direct contact between the positive and negative electrodes. The electrodes are positioned on the electricity collectors and
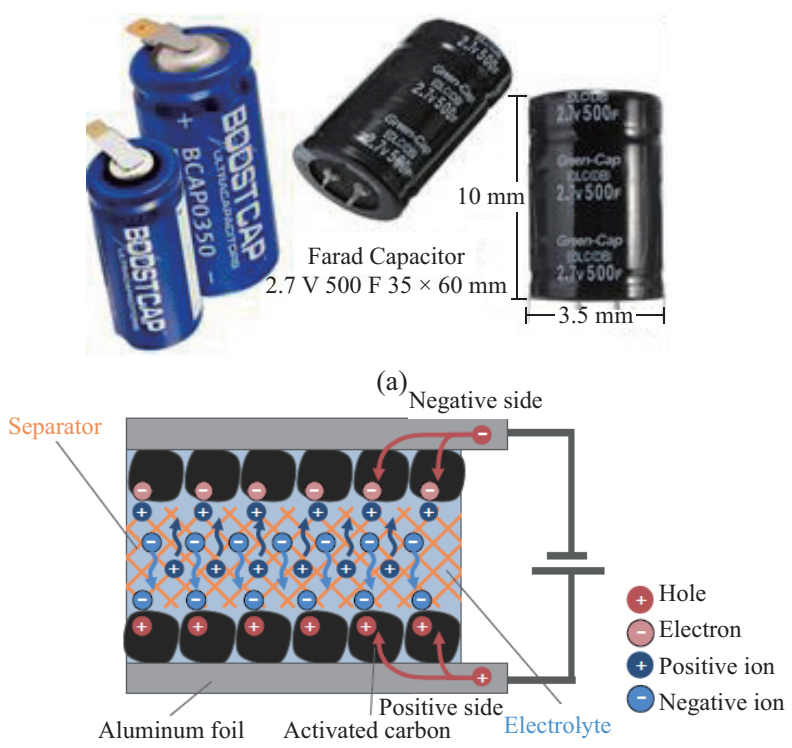

(b)

Fig. 1. (a) Some SCs to be obtained in the market. (b) The structure of SCs [19], [20].

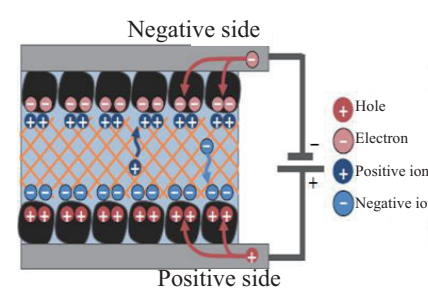

(a)

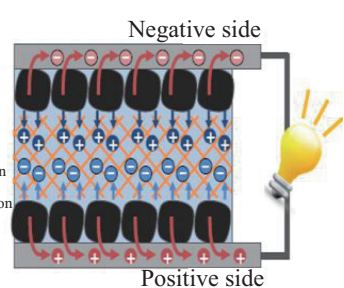

(b)
Fig. 2. (a) Charge. (b) Discharge state in SCs [20].

coated with activated carbon powder. An electrical double layer is formed at each interface where the active carbon powder contacts the electrolyte as shown in Fig. 1(b) [20]. The Stern layer accounts for the specific absorption of the ions on the electrode surface. The diffuse layer incorporates the GouyChapman model, and their combination is called a Gouy Chapman - Stern model [22].

When the SC is charged, the negative ions and vacancies on the positive electrode side and the positive ions and the electrons on the negative electrode side are aligned across the interface as shown in Fig. 2(a). This state of alignment of ions and electrons is called an electrical double-layer capacitor (EDLC) [20]. The capacitance value of SCs is depended on the surface area, and a large surface area has powdered activated carbons, which are used as an electrode material [21]. The SCs are charged by ions moving through the carbon surface and discharged by reverse moving away of ions is shown in Fig. 2(a) and (b) respectively [20].

\section{B. Performance Comparison With Other Energy Storage Technologies}

The main advantages and drawbacks of SCs are given in this section. The SCs have a high power density, but low energy density. The SCs are quick charging and discharging, but they 
TABLE I

Comparison Between the Battery, SC, and Electrolytic Capacitor Performances [16]

\begin{tabular}{lccc}
\hline \hline $\begin{array}{l}\text { Storage devises } \\
\text { characteristics }\end{array}$ & Battery & Supercapacitor & $\begin{array}{c}\text { Electrolytic } \\
\text { capacitor }\end{array}$ \\
\hline Charging time & $1<t<5 \mathrm{~h}$ & $1-30 \mathrm{~s}$ & $10^{-3}<t<10^{-6}$ \\
Discharging time & $t>0.3 \mathrm{~h}$ & $1-30 \mathrm{~s}$ & $10^{-3}<t<10^{-6}$ \\
The energy density (Wh/kg) & $10-100$ & $1-10$ & $<0.1$ \\
Lifetime (cycle number) & 1000 & $10^{6}$ & $10^{6}$ \\
Power density (W/kg) & $<1000$ & 10,000 & $>1,000,000$ \\
Charge/discharge efficiency & $0.7-0.85$ & $0.85-0.98$ & $>0.95$ \\
\hline \hline
\end{tabular}

have a very high self-discharge rate. It does not blow up in case of accidental direct short connection and stops accepting energy when it becomes fully charged. SCs have extended the lifetime and long shelf life and them environmentally safe and no gas emissions [4]. Table I presents a numerical comparison between the battery, SC, and electrolytic capacitor characteristics. Compared with the other commercially available energy storage technologies, the SCs usually offer a high-power density, high efficiency, fast charging and discharging speed, and long cycle lifetime [16]. On the other hand, the energy density of SC is limited compared to batteries. Accordingly, a combination of SCs and batteries may be required in some applications [49].

\section{Literature Review Focus on Supercapacitor Circuit Models}

For SCs systems, modeling is essential for the system dimensioning, condition monitoring, and controller design. Several SC models are available in the literature based on chemical, mathematical and electrical characteristics, aging, artificially intelligent, and the dynamic structure of SCs models [8]-[15], [22]. A simple electrical model of SCs for describing the behavior of SCs as a function of frequency, voltage, and temperature has also been discussed in [16]. Electrochemical models offer high accuracy but increase the calculation complexity. As an alternative, an equivalent circuit model derived from empirical and experimental data can also be used. These make them inadequate to demonstrate the SCs dynamics under different conditions. However, structural simplicity and decent modeling accuracy make the equivalent electrical circuit model suitable for real-time energy management simulations [22], [23].

The electrochemical model is known as a double-layer model since the structure of the $\mathrm{SC}$ has a double layer at the junction of a metal with an electrolyte solution, and the layer has two elements as shown in Fig. 1(b). The inner component, known as the "compact layer" or "Helmholtz layer" discovered by Helmholtz [24] and described the EDL phenomenon it using a model where all the charges were assumed to be absorbed in the electrode surface. The outer element, the "diffuse layer" or "Gouy-Chapman layer", is semi-infinite in extent and contains anions and cations distributed unequally. Gouy [25] and

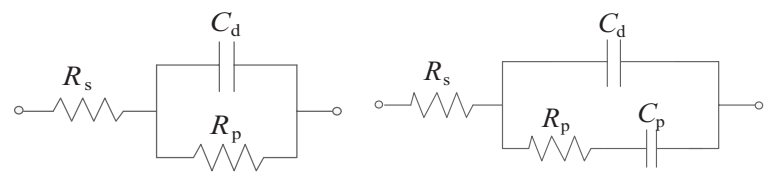

(a)

(b)

Fig. 3. (a) Classical SC model. (b) SC model using a Debye polarization.

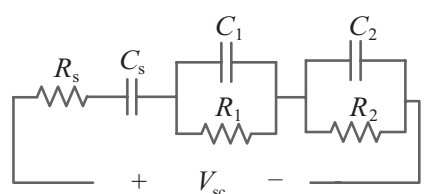

(a)

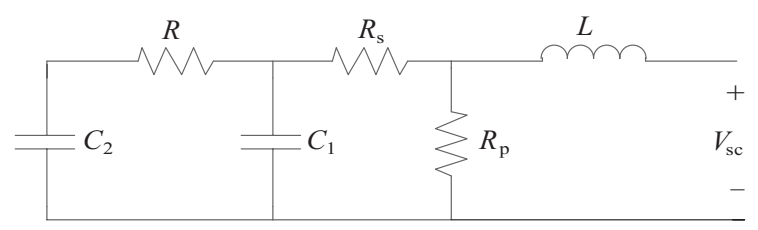

(b)

Fig. 4. (a) Conventional equivalent circuit model. (b) Adynamic model for SCs [34].

Chapman [26] further modified the Helmholtz model to account for the ion mobility in the electrolyte solutions as a result of diffusion and electrostatic forces. The model to describe the (metal)/(electrolyte solution) double layer was modified by Stern [27], [28].

Several circuit models have been proposed for SCs. The most often applied being the classical capacitor model [31], [32], where the simplified equivalent circuit is considered as actual capacitor behavior in a slow discharge as illustrated in Fig. 3(a). This circuit consists of a capacitance $\left(C_{\mathrm{d}}\right)$, the equivalent series resistance $\left(R_{\mathrm{s}}\right)$, which occurs during charging and discharging internal resistance, and an equivalent parallel resistance $\left(R_{\mathrm{p}}\right)$ to represent the path of leakage charge of SCs in a long-term effect [30]. Also, Nelms et al. described another approach where the SC characteristics are modeled using a Debye polarization cell, which is shown in Fig. 3(b) [33].

The conventional equivalent circuit model employs elementary electrical circuit elements to represent the SC dynamics is shown in Fig. 4(a) [23]. The basic model has a limitation since the capacitance of an $\mathrm{SC}$ is strongly dependent on terminal voltage in general [16], [34]. Therefore, a more effective model for SCs has been proposed in [34] based on the circuit diagram in Fig. 4(b). A more complex equivalent circuit model that represents the physical mechanisms in the SC has also been discussed in the literature. Such a model is known as a transmission line network model where the resistances and non-linear capacitances represent the distributed ESRs and electrostatic double-layer capacitance intrinsic to each pole in the electrode material. There are also additional resistances in the electrode material and a diffusion resistance in the membrane [35], [36].

Unfortunately, the equivalent circuits used in the detailed modeling of SCs mentioned above are not very suitable for 


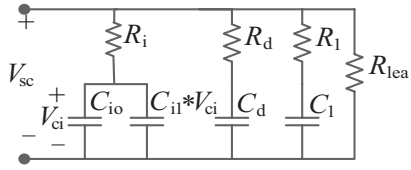

(a)

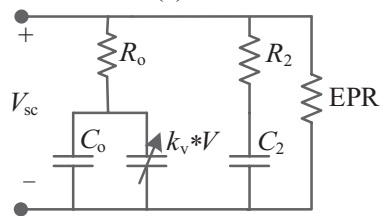

(b)

Fig. 5. The equivalent circuits of SCs. (a) Zubieta model. (b) Faranda model.

a power electronic simulation environment. Most of them require an intensive test to obtain the model parameters. These may not be suitable for an initial simulation study. Therefore, a simplified equivalent circuit that can capture the characteristic behavior of SCs under different operating conditions has been developed. Such a model implementing the variable capacitance feature is described by Zubieta et al. [15]. The model uses three separate RC time constants in three parallel branch networks, and a high resistance element to model cell leakage is illustrated in Fig. 5(a). The third or delayed branch parameters are $R_{\mathrm{d}}$ and $C_{\mathrm{d}}$. An improved version of the Zubieta model was proposed by Rafik [16], where the frequency-dependent parameters in the capacitor are taken into consideration. Faranda [10] is proposed a simplified version of the Zubieta model [15] with one RC-branch less than as shown in Fig. 5(b). According to [10], this model simplifies the estimation of parameters, reduces the number and complexity of measurements, and decreases the possibility of errors. Faranda also proposes a method of determining the parameters in the model based on measurements. The complexity of the parameters determined in the Zubieta model makes it difficult to be implemented. Therefore, using the simplified Faranda model gives adequate relevance with the measurements besides good accuracy.

The fractional-order equivalent circuit's model of SCs has also been developed in the previous research [23]. To further improve the model accuracy, a fractional-order calculus has been introduced for SC modeling applications [22]. When the SCs operate under high rate cycling, they may generate high heat depend on low internal resistance. This operation affects the performance and lifetime of SCs, which are very sensitive to temperature change. Therefore, several studies focused on the temperature model of SCs [16], [37]-[40]. Intelligent modeling techniques such as an artificial neural network (ANN) and fuzzy logic have been successfully utilized to predict the performance of energy storage systems include batteries and SCs [41], [42]. Temperature, voltage, and current are the parameters of the accelerating aging of SCs and define the lifetime. A simplified thermal model of the SC to estimate the core temperature and the case temperature of the components is proposed [43], [44].

Although all these models include more details and different applications, this paper focused on the equivalent circuit model designed by Zubieta and Faranda for simulations, which will

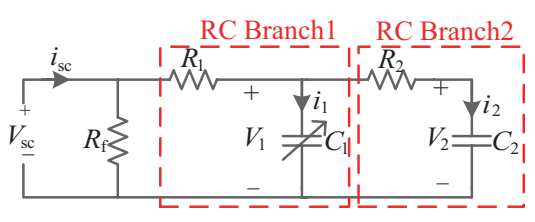

Fig. 6. SC two branches circuit model.

be very suitable for power electronic applications. This model doesn't need an intensive test for accuracy. Moreover, the structural simplicity and decent modelling accuracy make the equivalent electrical circuit model very suitable for power electronic applications and real-time energy management simulations [51].

\section{Proposed Supercapacitor Circuit Model}

Several studies in the literature investigate the chemical, mathematical, and electrical stimulation model of SCs [8]-[15]. The SCs module simulation was based on two RC branches' electrical circuit models as shown in Fig. 6, which includes the module structure and its mathematical equation simulation in this study [5], [15], [16]. This circuit is simplified by neglecting the leakage current of SC as given in (1). The $U_{\mathrm{SC}}$ and $I_{\mathrm{SC}}$ are the SC module voltage and currents respectively. The $v_{\mathrm{SC}}$, $i_{\mathrm{SC}}, N_{\mathrm{S} \_\mathrm{SC}}$, and $N_{\mathrm{P} \_\mathrm{SC}}$ are the SC primary voltage and current, series elements, and parallel branches respectively. The first capacitance $C_{1}$ depends on the voltage $v_{1}$ and consists of a constant capacity $C_{0}$ and a fixed parameter $C_{\mathrm{V}}$, and it is written as $C_{1}=C_{0}+C_{\mathrm{v}} v_{1}$. The $R_{1} C_{1}$ branch determines the immediate behavior of the SC during rapid charge and discharge cycles in a few seconds. The $R_{2} C_{2}$ cell is the slow branch and completes the first cell in the longtime range and describes the internal energy distribution at the end of the charge. The equivalent parallel resistance $R_{f}$ represents the leakage current and can be neglected during fast charge/discharge applications [5].

$U_{\mathrm{SC}}=N_{\mathrm{S} \_\mathrm{SC}} v_{\mathrm{SC}}=N_{\mathrm{S} \_\mathrm{SC}}\left(v_{1}+R_{1} i_{\mathrm{SC}}\right)=N_{\mathrm{S} \_\mathrm{SC}}\left(v_{1}+R_{1} \frac{I_{\mathrm{SC}}}{N_{\mathrm{P} \_\mathrm{SC}}}\right)(1)$

The relationship between quick charge $\left(Q_{1}\right)$ and voltage $\left(v_{1}\right)$ is shown in (2) depend on current $\left(i_{1}\right)$. The charge $\left(Q_{1}\right)$ is shown in (3). The inverse relationship between $v_{1}$ and $Q_{1}$ the equation can be obtained as in (4), which considers the equivalent electric circuit with two RC branches proposed by Zubieta and Bonert [36], Rafik et al. [37] to obtain this equation.

$$
\begin{gathered}
i_{1}=C_{1} \frac{\mathrm{d} v_{1}}{\mathrm{~d} t}=\frac{\mathrm{d} Q_{1}}{\mathrm{~d} t}=\left(C_{0}+C_{\mathrm{V}} v_{1}\right) \frac{\mathrm{d} v_{1}}{\mathrm{~d} t} \\
Q_{1}=C_{0} v_{1}+\frac{1}{2} C_{\mathrm{V}} v_{1}^{2} \\
v_{1}=\frac{-C_{0}+\sqrt{C_{0}^{2}+2 \mathrm{C}_{\mathrm{V}} Q_{1}}}{C_{\mathrm{V}}}
\end{gathered}
$$

(1) and (4) are combined as in (5). 


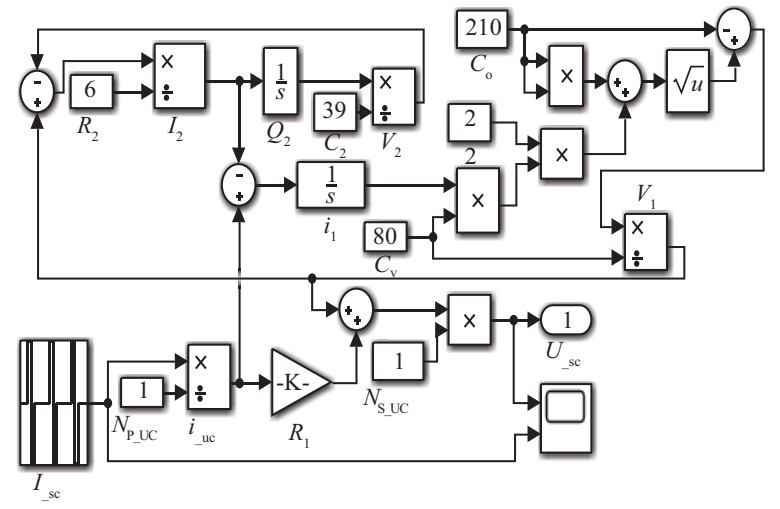

(a)

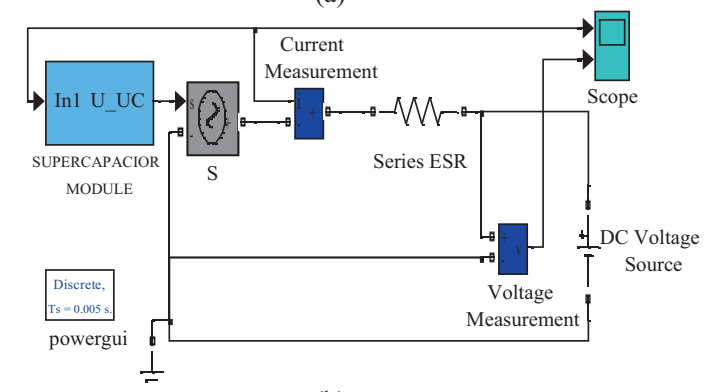

(b)

Fig. 7. (a) Module model. (b) Electrical model of an SC in Matlab/Simulink.

$$
\begin{aligned}
& U_{\mathrm{SC}}=N_{\mathrm{S}_{-} \mathrm{SC}} v_{\mathrm{SC}}=N_{\mathrm{S} \_\mathrm{SC}}\left(v_{1}+R_{1} i_{\mathrm{SC}}\right)= \\
& N_{\mathrm{S} \_\mathrm{SC}}\left(\frac{-C_{0}+\sqrt{C_{0}^{2}+2 \mathrm{C}_{\mathrm{V}} Q_{1}}}{C_{\mathrm{V}}}+R_{1} \frac{I_{\mathrm{SC}}}{N_{\mathrm{P} \mathrm{SC}}}\right)
\end{aligned}
$$

The voltage $\left(v_{2}\right)$ in the secondary capacity $\left(C_{2}\right)$ is described in (6).

$$
v_{2}=\frac{Q_{2}}{C_{2}}=\frac{1}{C_{2}} \int i_{2} \mathrm{~d} t=\frac{1}{C_{2}} \int \frac{1}{R_{2}}\left(v_{1}-v_{2}\right) \mathrm{d} t
$$

These equations are designed in Matlab/Simulink as an SC module model as shown in Fig. 7(a). The (5) and (6) are modified for $310 \mathrm{~F}$ capacitor coefficients in the simulation. These coefficients are obtained and calculated in previous studies experimental values and datasheets [45], [50]. This values are $R_{1}=5.5 \mathrm{~m} \Omega, R_{2}=6 \Omega, C_{0}=210 \mathrm{~F}, C_{\mathrm{V}}=80 \mathrm{~F} / \mathrm{V}, C_{2}=$ $39 \mathrm{~F}$ for $310 \mathrm{~F}$ SCs. Identification of coefficients of different capacitors is given in the next section more detailed. An SC electrical model for simulations of power systems is shown in Fig. 7(b).

To identify the parameters of the proposed model a charge and discharge test at constant current have been carried out. The experimental method which determines the coefficient of the SC equivalent circuit is described firstly by Zubieta and Bonert [5]. In the proposed model, the parameters are identified by charging the DLC from zero to rated voltage and by observing the terminal voltage during the internal charge redistribution over the time of $30 \mathrm{~min}$. The process to identify the parameters assumes that this condition of zero charges is present at the beginning. The approach to determine the
TABLE II

The Paramerers and Their Coefficients for Different SC Measurements [5], [10]

\begin{tabular}{lcccccc}
\hline \hline Parameters & \multicolumn{3}{c}{ Zubieta and Bonert } & \multicolumn{4}{c}{ Faranda et al } \\
\hline Capacitor Value & $470 \mathrm{~F}$ & $1500 \mathrm{~F}$ & $110 \mathrm{~F}$ & $200 \mathrm{~F}$ & $350 \mathrm{~F}$ & $600 \mathrm{~F}$ \\
\hline $\mathrm{R}_{\mathrm{i}}, \mathrm{R}_{\mathrm{o}}(\mathrm{m} \Omega)$ & 2.5 & 1.5 & 10 & 8.8 & 4.8 & 2.8 \\
$\mathrm{C}_{\mathrm{i}_{\mathrm{o}}}, \mathrm{C}_{\mathrm{o}}(\mathrm{F})$ & 270 & 900 & 89 & 158 & 232 & 454 \\
$\mathrm{C}_{\mathrm{i}}(\mathrm{F} / \mathrm{V})$ & 190 & 600 & 29 & 56 & 90 & 176 \\
$\mathrm{R}_{\mathrm{d}}, \mathrm{R}_{2}(\Omega)$ & 0.9 & 0.4 & 17.5 & 8.8 & 5.5 & 3.1 \\
$\mathrm{C}_{\mathrm{d}}, \mathrm{C}_{2}(\mathrm{~F})$ & 100 & 200 & 13.7 & 27.5 & 43.2 & 77.4 \\
$\mathrm{R}_{1}(\Omega)$ & 5.2 & 3.2 & - & - & - & - \\
$\mathrm{C}_{1}(\mathrm{~F})$ & 220 & 330 & - & - & - & - \\
$\mathrm{R}_{\text {lea }}, \mathrm{EPR}(\mathrm{k} \Omega)$ & 9 & 4 & 5 & 5 & 2.5 & 2.5 \\
\hline \hline
\end{tabular}

different equivalent circuit model parameters is based on the fact that the three equivalent branches: the immediate branch, delayed branch, and long-term branch have distinctly different time constants considering the coefficient identifications. Table II shows the average of the equivalent model parameter values measured for the two types of double-layer capacitors. [15].

The other experimental method to define the coefficients is described in [10]. In the first step, the values of the parameters of the immediate branch are determined. The $R_{0}$ resistance is calculated by measuring the potential difference $\Delta V$ between the two terminals during the first charge moment and subdividing it for the total charge current, assuming all the capacitances are still discharged. The two components of the total capacitance of the short-term branch are determined through a unique procedure. To validate the proposed model, seven models of SCs and their coefficients are tested as shown in Table II. According to the results, it can be noticed that capacitors of the same type and size can have different parameter values of the equivalent circuit [10].

\section{The Test of Supercapacitor Model and Simulations in Matlab/Simulink}

The SC model is simulated and compared with the capacitance/ ESR measurements and cycle life waveforms from the datasheet of 310 F SCs [46]. The ideal Capacitance/ESR measurements waveforms for data sheets are given in Fig. 8 (a), and cycle life waveform measurements for data sheets are given in Fig. 8(b).

In datasheet $V_{1}=V_{\text {rated }}=2.7 \mathrm{~V}, V_{3}=0.5 x V_{\text {rated }}=1.35 \mathrm{~V}, t_{2}-$ $t_{1}=15 \mathrm{~s}, t_{4}-t_{3}=5 \mathrm{~s}$ are given for Fig. 8 (a). The $t_{3}-t_{2}$ value is calculated from capacitance (7). $T_{\text {charge }}$ is calculated as a 26 second for 0 to $t_{1}$.

$$
\begin{aligned}
\text { Capacitance } & =I \frac{\Delta t}{\Delta V} \rightarrow \Delta t=\frac{C V}{I} \rightarrow t_{3}-t_{2}=\frac{C\left(V_{2}-V_{3}\right)}{I} \\
& =\frac{310(2.7-1.3)}{31}=14 \mathrm{~s}
\end{aligned}
$$

$V_{1}=V_{\text {rated }}=2.7 \mathrm{~V}, V_{2}=0.5 V_{\text {rated }}=1.35 \mathrm{~V}, t_{2}-t_{1}=5 \mathrm{~s}, t_{4}-t_{3}$ $=15 \mathrm{~s}$ are given for Fig. 8(b) in data sheets.

For these tests, a constant current source is used in charging, discharging, and zero current modes, and voltage variations are observed. The simulation result for the capacitor/ESR 


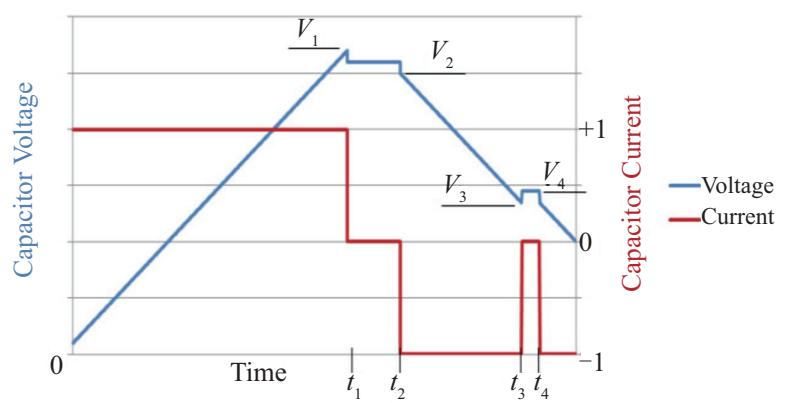

(a)

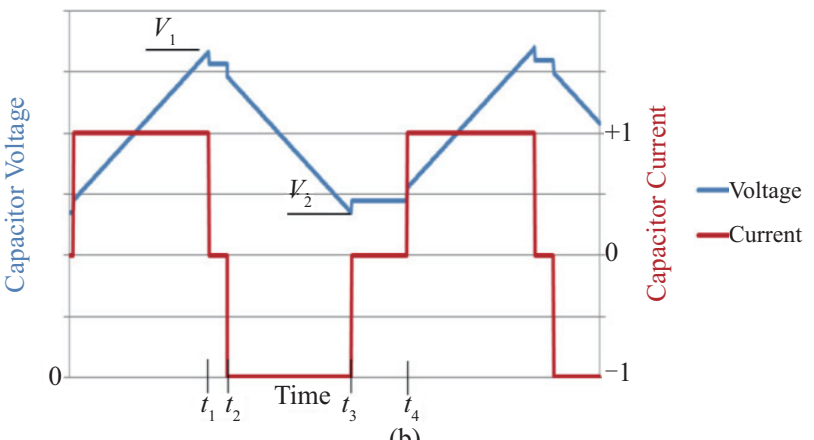

Fig. 8. (a) Capacitance/ESR. (b) Cycle life waveform measurements in datasheet [46].
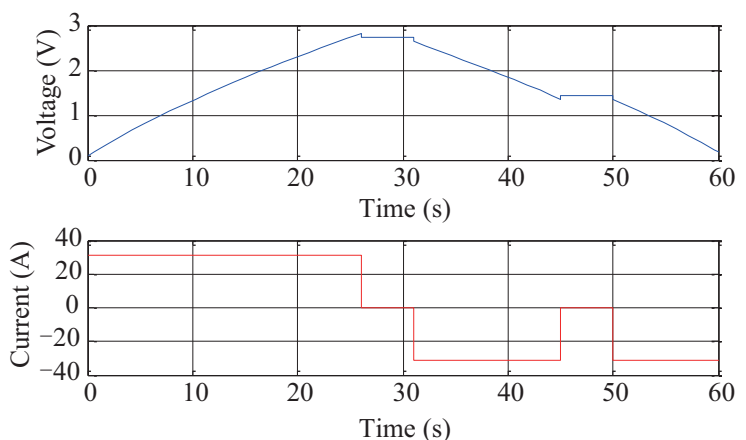

(a)
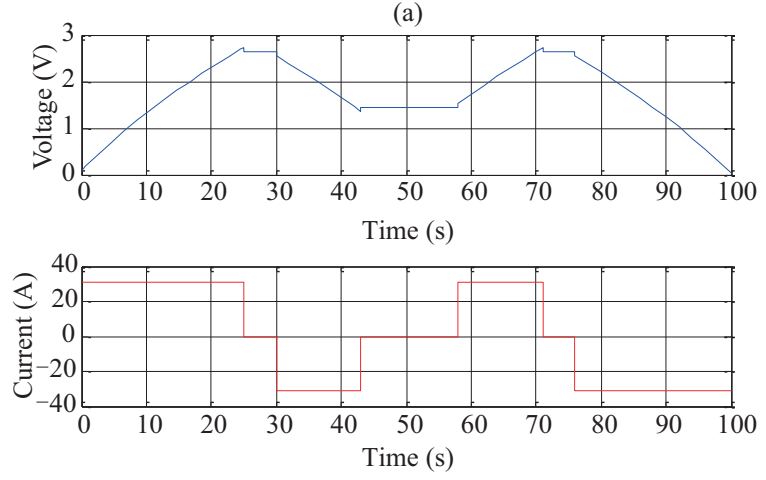

(b)

Fig. 9. (a) CAP/ESR. (b) Cycle life waveforms simulation results for $310 \mathrm{~F} \mathrm{SCs.}$

measurement waveform is shown in Fig. 9(a), and the cycle life waveform is shown in Fig. 9(b) for 310 F SCs. The simulation results are seen suitable for the experimental results and calculations in Fig. 8 manufacturer datasheets, and this shows the SC model works correctly. The simulation result for
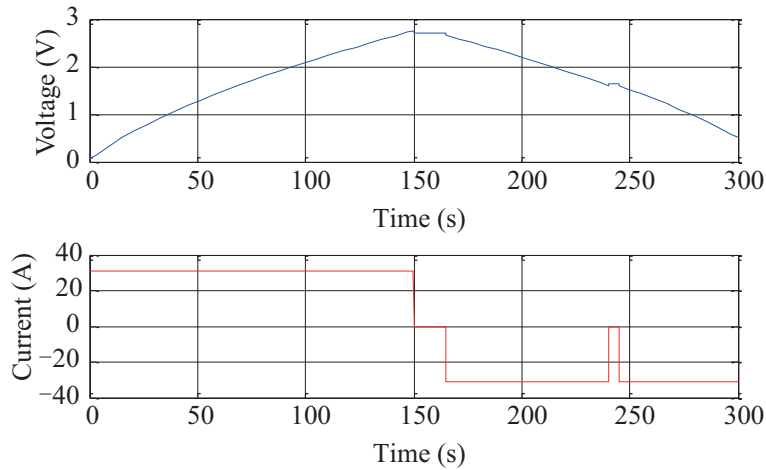

(a)
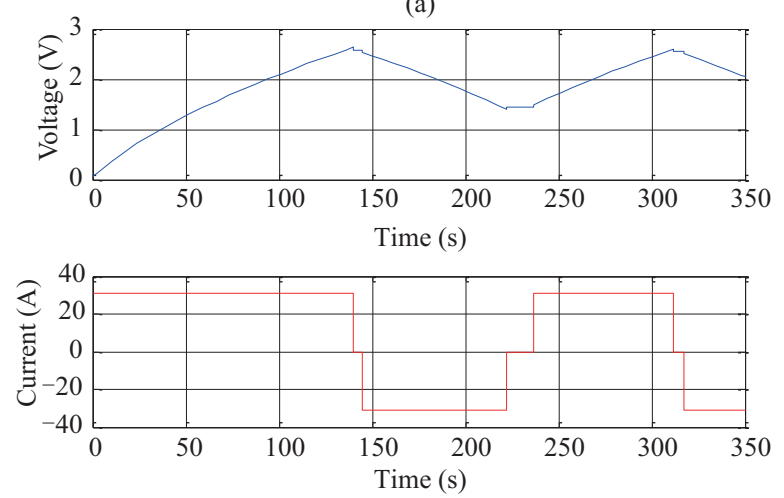

(b)

Fig. 10. (a) CAP/ESR. (b) Cycle life waveforms simulation results for $1500 \mathrm{~F}$ SCs.

the capacitor/ESR measurement waveform is shown in Fig. 10 (a) and cycle life waveform is shown in Fig. 10(b) for $1500 \mathrm{~F}$ SCs. The charge and discharge cycle time of this SC is longer than the first one as expected. Also, the charge and discharge times are compared with datasheet values quantitatively.

The simulation results of the SC charge and discharge test circuit are shown in Fig. 11(a) and (b) for a specific series charge ESR and discharge load resistance. The test circuit turns from charge mode to discharge mode at $600 \mathrm{~s}$ for the $310 \mathrm{~F}$ $\mathrm{SC}$ model, and at $1500 \mathrm{~s}$ for $1500 \mathrm{~F} \mathrm{SC}$ model. The charge and discharge simulation results of a $310 \mathrm{~F} \mathrm{SC}$ model are shown in Fig. 11(a). The SC voltage reaches $2.7 \mathrm{~V}$ and fixed its charge mode. The current and power go to zero with time. Adversely in the discharge mode, the SC voltage, current, and power go to zero with time. The SCs charged in $300 \mathrm{~s}$ and discharged $100 \mathrm{~s}$ depending on resistances. The charge and discharge simulation results of the $1500 \mathrm{~F} \mathrm{SC}$ model are shown in Fig. 11(b). The SCs charged in $1000 \mathrm{~s}$ and discharged $500 \mathrm{~s}$ depending on the resistance. The maximum power in charge mode reaches $20 \mathrm{~W}$, and in discharge mode reaches $70 \mathrm{~W}$ depend on ESR resistance and discharge load resistance. The ESR resistance is select 0.1 $\Omega$, and the load resistance is selected $0.01 \Omega$ for the simulation set up. These results are seen suitable with theoretical and experimental results in datasheets and with the other studied model results in the literature [5]-[16], [46].

The supercapacitor test circuit with an experimental setup is given in Fig. 12(a) and (b). A DC power supply and a variable load are used to charge the SC module. The designed supercapacitor module is consists of two blocks and five-piece $310 \mathrm{~F}, 2.7 \mathrm{~V} \mathrm{SCs}$. In the first step, the DC power supply is 


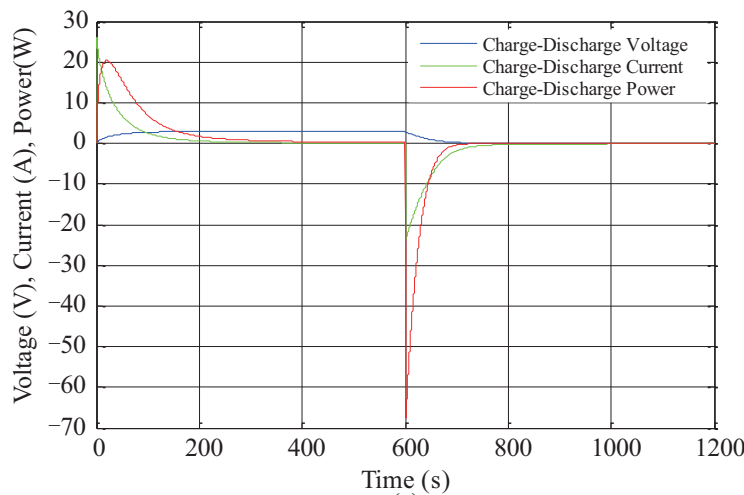

(a)

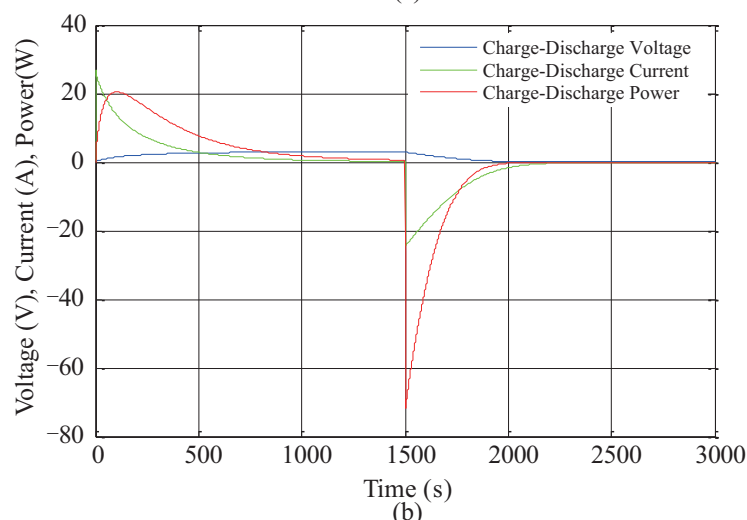

(b)

Fig. 11. The SC charge and discharge circuit simulation results for $310 \mathrm{~F}$ (a), and $3000 \mathrm{~F}(\mathrm{~b})$.

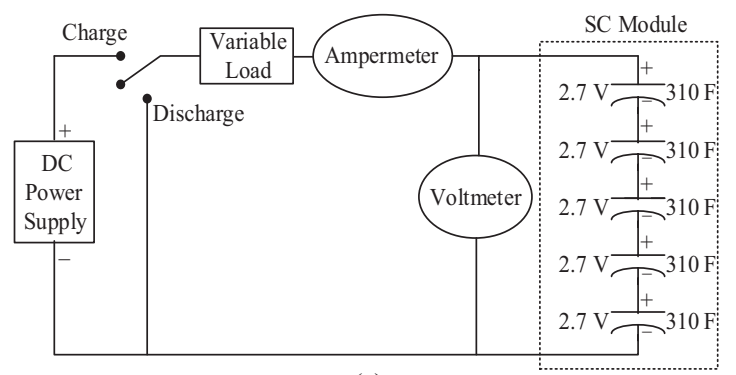

(a)

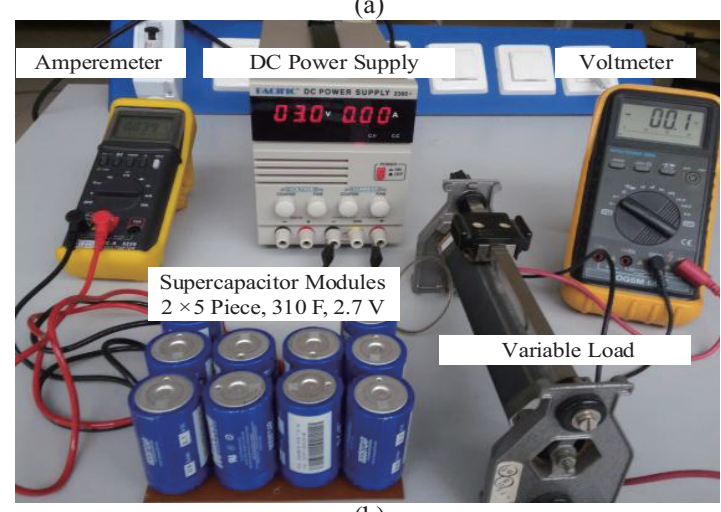

(b)

Fig. 12. SCs testing circuit diagram (a), Experimental setup (b).

used, and the variable load setting to $0.01 \Omega$ as the same with simulations and charged the SC. In the second step, the SCs are discharged using the same variable load. The amperemeter

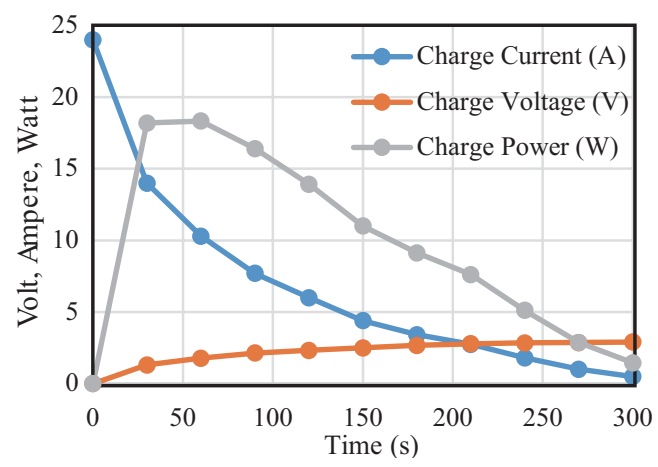

(a)

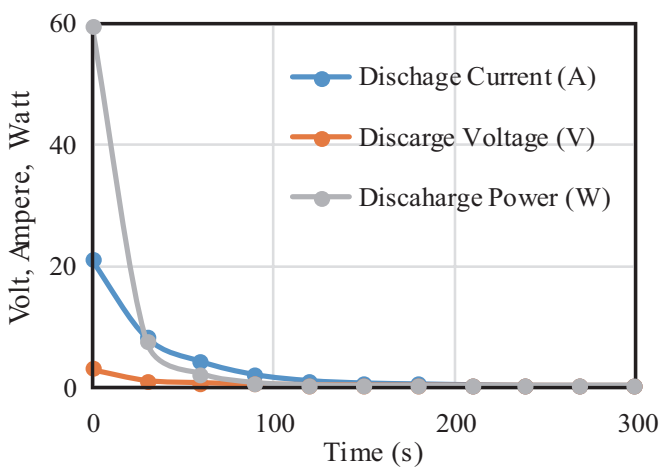

(b)

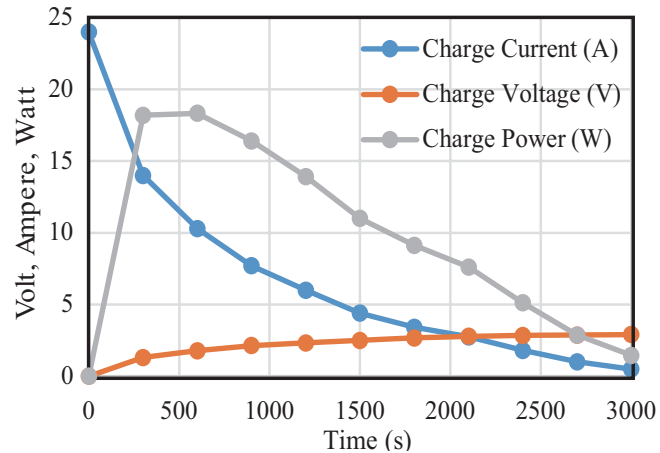

(c)

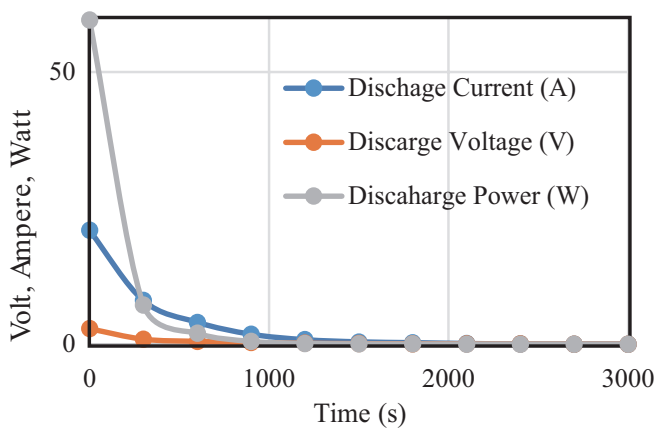

(d)

Fig. 13. The experimental results show for $310 \mathrm{~F}$ (a) charge, (b) discharge, and $3000 \mathrm{~F}$ (c) charge and (d) discharge voltage, current, and power variations.

precision is $\pm 1.5 \%$, and the voltmeter precision is $\pm 1 \%$ is given in user manuals. Also, the results are compatible with the power supplies amperemeter and voltmeter. The power values are calculated from voltage and current measurements. The 
experimental measurement results are shown in Fig. 13(a)(d) for the charge and discharge. The experimental results obtained for single $310 \mathrm{~F}$ SC is shown in Fig. 13(a) and (b), and for a 3000 F SC is shown in Fig. 13 (c) and (d) where the charge and discharge voltage, current, and power variations are demonstrated. The charge and discharge time is increased nearly ten times for $3000 \mathrm{~F} \mathrm{SC}$ depending on the time constant. As a result, the experimental and simulation results are seen as suitable as expected.

\section{Conclusions}

In this paper, the principle of SCs and their chemical structure, the advantages, and disadvantages of SCs, basic specifications, and performance comparison of SCs with the batteries and electrolytic capacitors are presented. Different $\mathrm{SC}$ models available in the literature are investigated in terms of their specifications and design applications. The voltage-current equation of the SC module using the SC simplified circuit model is proposed in this study. The experimental methods which determine the parameters of the $\mathrm{SC}$ equivalent circuit are provided for different capacitors, and the method to obtain the model parameters are presented. Using this parameter and voltage-current equations, the SC Matlab/Simulink model was designed and simulated. The characteristics curves of Capacitance-ESR measurement and cycle life are obtained and compared with datasheets. Also, charge and discharge characteristics of SCs for different capacitor values are simulated to compare the power and energy density of SC modules. Moreover, a supercapacitor test circuit is used to test the charge and discharge of SC modules. The results show a good agreement between the model and the datasheets, and the designed models can be used for different electrical applications as a storage system. The supercapacitors (SCs) model can be used as an alternating storage device, for instantaneous energy storage in renewable energy applications.

\section{REFERENCES}

[1] M. Palacín and A. D. Guibert, "Why do batteries fail?," in Science, vol. 351, no. 6273, pp. 574-583, Feb. 2016.

[2] F. Díaz-González, A. Sumper, O. Gomis-Bellmunt, and R. VillafáfilaRobles, "A review of energy storage technologies for wind power applications," in Renewable and Sustainable Energy Reviews, vol. 16, no. 4, pp. 2154-2171, May 2012.

[3] Y. Zou, X. Hu, H. Ma, and S. E. Li, "Combined state of charge and state of health estimation over lithium-ion battery cell cycle lifespan for electric vehicles," in Journal of Power Sources, vol. 273, pp. 793-803. Jan. 2015.

[4] M. E. Glavin and W. G. Hurley, "Optimizations of a photovoltaic battery ultracapacitor hybrid energy storage system," in Solar Energy, vol. 86, no. 10, pp. 3009-3020, Oct. 2012,

[5] A. Lahyani, P. Venet, A. Guermazi, and A. Troudi, "Battery/ supercapacitors combination in uninterruptible power supply (UPS)," in IEEE Transactions on Power Electronics, vol. 28, no. 4, pp. 1509-1522. Apr. 2013

[6] A. Rufer, and P. A. Barrade, "Supercapacitor-based energy-storage system for elevators with soft commutated interface," in IEEE Transactions on Industry Applications, vol. 38, no. 5, pp. 1151-1159, Sep./Oct. 2002.

[7] S. Mallika and R. S. Kuma, "Review on ultracapacitor-battery interface for energy management system," in International Journal of Engineering and Technology, vol. 3, no. 1, pp. 37-43, Feb. 2011.
[8] P. Johansson and B. Andersson, "Comparison of simulation programs for supercapacitor modelling," M. S. Thesis, Chalmers University of Technology, Sweden, 2008.

[9] M. Michalczuk, L. Grzesiak, and M. B. Ufnalski, "Experimental parameter identification of Battery-ultracapacitor energy storage system," in Proccedings of 24th International Symposium on Industrial Electronics (ISIE), June 2015, pp. 1260-1265.

[10] R. Faranda, M. Gallina, and D. T. Son, "A new simplified model of double-layer capacitors," in Proccedings of International Conference on Clean Electrical Power, May 2007, pp. 706-710.

[11] V. A. Shah, P. Kundu, and R. Maheshwari, "Improved method for characterization of ultracapacitor by constant current charging," in International Journal of Modeling and Optimization, vol. 2, no. 3, pp. 290-294, Jun. 2012.

[12] S. Buller, E. Karden, D. Kok, and R. W. De Doncker, "Modeling the dynamic behavior of SCs using impedance spectroscopy," in IEEE Transactions on Industry Applications, vol. 38, no. 6, pp. 1622-1626, Nov./Dec. 2002.

[13] Z. L. Cheng, W. R. Chen, Q. Li, Z. L. Jiang, and Z. H. Yang, "Modeling and dynamic simulation of an efficient energy storage componentsupercapacitor," in Proccedings of Power and Energy Engineering Conference (APPEEC 2010 Asia-Pacific), Mar. 2010, pp. 1-4.

[14] M. S. Islam, M. B. Hossain, M. N. Hossain, S. B. Alam, M. Enamul, and H. Chowdhury, "Modeling of a double-layer capacitor with individual branch response," in Proceedings of the World Congress on Engineering and Computer Science, San Francisco, USA, vol. 2, Oct. 2010.

[15] L. B. Zubieta, "Characterization of double-layer capacitors for power electronics applications," in IEEE Transactions on Industry Applications, vol. 36, no. 1, pp. 199-205. Jan./Feb. 2000.

[16] F. Rafik, H. Gualous, R. Gallay, A. Crausaz, and A. Berthon, "Frequency, thermal and voltage supercapacitor characterization and modeling," in Journal of Power Sources, vol. 165, no. 2, pp. 928-934. Mar. 2007,

[17] L. B. Zubieta, "Characterization of double-layer capacitors for power electronics applications," Ph.D. dissertation, University of Toronto, Canada, 1997.

[18] A. Burke, "Ultracapacitor: why, how, and where is the technology," in Journal of Power Sources, vol. 91, no. 1, pp. 37-50, Nov. 2000.

[19] Maxwell Corp, BC Series Ultra-Capacitor, (2013), Data Sheet, Doc. No: 1017105.2, [Online]. Available: https://www.maxwell.com/images/ documents/bcseries_ds_1017105-4.pdf.

[20] Murata Manufacturing Co., Ltd., (2018), Supercapacitor (EDLC) Basics (Part 1): What is a supercapacitor (EDLC)? [Online]. Available: https://www.murata.com/ /media/webrenewal/products/capacitor/edlc/ techguide/electrical/edlc_technical_note.pdf.

[21] Y. Zhang, H. Feng, X. Wu, L. Wang, A. Zhang, T. Xia, H. Dong, X. Li, and L. Zang, "Progress of electrochemical capacitor electrode materials: A review," in International Journal of Hydrogen Energy, vol. 34, no. 11, pp. 4889-4899, Jun. 2009.

[22] L. Zhang, X. Hu, Z. Wang, F. Sun, and D. G. Dorrell, "A review of supercapacitor modeling, estimation, and applications: A control/ management perspective," in Renewable and Sustainable Energy Reviews, vol. 81, no. 2, pp. 1868-1878, Jan. 2018.

[23] C. Zou, L. Zhang, X. Hu, Z. Wang, T. Wik, and M. Pecht, "A review of fractional-order techniques applied to lithium-ion batteries, lead-acid batteries, and supercapacitors," in Journal of Power Sources, vol. 390, pp. 286-296, Jun. 2018.

[24] H. Helmholtz, "Studien suber electrische grenzschichten," in J. Phys. Theor. Appl., vol. 8, no. 1, pp. 376-382, 1879.

[25] G. Gouy, "Constitution of the electric charge at the surface of an electrolyte," in J. Phys. Theor. Appl., vol. 9, no. 4, pp. 457-67, 1910.

[26] D. L. Chapman, "A contribution to the theory of electro capillarity," in Philos. Mag. Ser. 6, vol. 25, no. 148, pp. 475-481, 1913.

[27] H. O. Stern, "The theory of the electrolytic double shift," in $Z$ Elektrochem and Angew Phys. Chem., vol. 30, pp. 508-516, Nov. 1924.

[28] K. B. Oldham, "A Gouy-Chapman-Stern model of the double layer at a (metal)/(ionic liquid) interface," in Journal of Electroanalytical Chemistry, vol. 613, no. 2, pp. 131-138, Feb. 2008,

[29] L. H. Seim, "Modeling, control and experimental testing of a SC/Battery hybrid system: Passive and semi-active topologies," M. S. Thesis, Department of Mathematical Sciences and Technology, Norwegian University of Life Sciences, Oslo, Norway, 2012. 
[30] A. M. Jarushi, "Analysis and modelling of energy source combinations for electric vehicles," Ph.D. Dissertation, University of Manchester, Manchester, UK, 2010.

[31] L. Spyker, R. M. Nelms, "Classical equivalent circuit parameters for a double layer capacitor," in IEEE Transactions on Aerospace and Electronic Systems, vol. 36, no. 3, pp. 829-836, Jul. 2000.

[32] M. Pagano, and L. Piegari, "Hybrid electrochemical power sources for on-board applications," in IEEE Transactions on Energy Conversion, vol. 22, no. 2, pp. 450-456, May 2007.

[33] R. M. Nelms, D. R. Cahela, and B. J. Tatarchuk, "Using a Debye polarization cell to predict double-layer capacitor performance," in IEEE Transactions on Industry Applications, vol. 37, no. 1, pp. 4-9. Jan.Feb. 2001.

[34] B. Vural, M. Uzunoglu, O. Erdinc, O. C. Onar, "A dynamic ultracapacitor model for vehicular applications," in Proccedings of 2009 International Conference on Clean Electrical Power, Jun. 2009, pp. 595-598.

[35] Y. Yao, D. Zhang, and D. Xu, "A study of supercapacitor parameters and characteristics," in Proccedings of 2006 International Conference on Power System Technology, Oct. 2006, pp. 1-4.

[36] S. Atcitty, "Electrochemical capacitor characterization for electric utility applications," Ph.D. Dissertation, Virginia Polytechnic Institute, and State University, USA, 2006.

[37] H. Gualous, H. Louahlia, and R. Gallay, "Supercapacitor characterization and thermal modelling with reversible and irreversible heat effect," in IEEE Transactions on Power Electronics, vol. 26, no. 11, pp. 3402-3409, Nov. 2011.

[38] K. Wang, L. Zhang, B. Ji, and J. Yuan, "The thermal analysis on the stackable supercapacitors," in Energy, vol. 59, pp. 440-444. Sept. 2013.

[39] A. D'entremont, and L. Pilon, "First-principles thermal modeling of electric double-layer capacitors under constant-current cycling," in Journal of Power Sources, vol. 246, pp. 887-898. Jan. 2014,

[40] M. Sakka, H. Gualous, J. Mierlo, H. Culcu, "Thermal modeling and heat management of supercapacitor modules for vehicle applications," in Journal of Power Sources, vol. 194, no. 2, pp. 581-587, Dec. 2009.

[41] A. Soualhi, A. Sari, H. Razik, P. Venet, G. Clerc, R. German, O. Briat, J. Vinassa, "Supercapacitors aging prediction by neural networks," in Proceedings of the 39th IEEE Industrial Electronics Society Annual Conference, Vienna, Austria, 2013, pp. 6812-6818.

[42] H. Farsi, and F. Gobal, "Artificial neural network simulator for supercapacitors performance prediction," in Computational Material Science, vol. 39, no. 3, pp. 678-683, May 2007.

[43] A. Hijazi, P. Kreczanik, E. Bideaux, P. Venet, G. Clerc, and M. Di Loreto, "Thermal network model of SC stack," in IEEE Transactions on Industrial Electronics, vol. 59, no. 2, pp. 979-987. Feb. 2012.

[44] P. Kreczanik, P. Venet, A. Hijazi, and G. Clerc, "Study of supercapacitor aging and lifetime estimation according to voltage, temperature, and RMS current," in IEEE Transactions on Industrial Electronics, vol. 61, no. 9, pp. 4895-4902, Sept. 2014,

[45] Y. Y. Chia, "Integrating SCs into a hybrid energy system to costs using the genetic algorithm (GA) and support vector machine," Ph.D. Dissertation, University of Nottingham, UK, 2014.

[46] Maxwell Technologies, BC Series Supercapacitors, (Nov. 2018), Datasheet, Document Number: 1017105.4, [Online]. Available: http:// www.maxwell.com/images/documents/bcseries_ds_1017105-4.pdf.

[47] Y. Yang, A. Sangwongwanich, and F. Blaabjerg, "Design for reliability of power electronics for grid-connected photovoltaic systems," in CPSS Transactions on Power Electronics and Applications, vol. 1, no. 1, pp. 92-103, Dec. 2016.

[48] A. Stippich, C. H. Van Der Broeck, A. Sewergin, A. H. Wienhausen, M. Neubert, P. Schülting, S. Taraborrelli, H. Van Hoek, and R. W. Doncker, "Key components of modular propulsion systems for next-generation electric vehicles," in CPSS Transactions on Power Electronics and Applications, vol. 2, no. 4, pp. 249-258, Dec. 2017.

[49] L. Chang, W. Zhang, S. Xu, and K. Spence, "Review on distributed energy storage systems for utility applications," in CPSS Transactions on Power Electronics and Applications, vol.2, no. 4, pp. 267-276, Dec.2017.

[50] M. E. Şahin, F. Blaabjerg, A. Sangwongwanich, "Predesign simulation of supercapacitors based on simplified equivalent circuit model," in Proceedings of Cyseni 2019 Conference, Kaunas, Lithuania, May 23-24, 2019.
[51] M. E. Şahin, F. Blaabjerg, "A hybrid PV-battery/supercapacitor system and a basic active power control proposal in MATLAB/Simulink," in Electronics, vol. 9, no. 1. pp. 129(1-18), Jan. 2020.

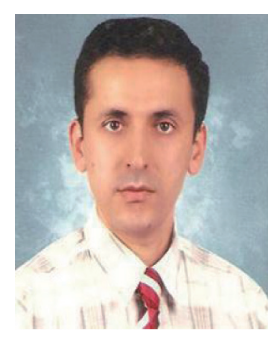

Mustafa Ergin Şahin was born in 1978 in Trabzon, Turkey. He received his B.Sc. degree in Electrical \& Electronics Engineering from Karadeniz Technical University (KTU), M.Sc. degree from Gazi University in Ankara and Ph.D. degree from KTU, Trabzon, Turkey, in 2002, 2006 and 2014, respectively. He was a Guest Researcher with TUBITAK 2219 postdoctoral research program at the Department of Energy Technology, Aalborg University from September 2018 to September 2019. He is currently an associate professor in Electrical and Electronics Engineering Department at RTE University. He was worked at different projects on low voltage power systems and relay manufacturer for power systems. He is an active reviewer for scientific journals in the field. He is also member of the Chamber of Electrical Engineers in Turkey. His main research interests are power electronics and utilization of renewable energy. He is the author of two books in circuit analysis and measurement, electronics laboratory.

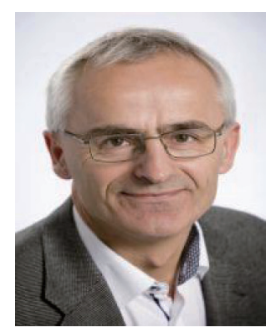

Frede Blaabjerg was with ABB-Scandia, Randers, Denmark, from 1987 to 1988 . From 1988 to 1992, he got the Ph.D. degree in Electrical Engineering at Aalborg University in 1995. He became an Assistant Professor in 1992, an Associate Professor in 1996, and a Full Professor of power electronics and drives in 1998. From 2017 he became a Villum Investigator. He is honoris causa at University Politehnica Timisoara (UPT), Romania and Tallinn Technical University (TTU) in Estonia.

His current research interests include power electronics and its applications such as in wind turbines, PV systems, reliability, harmonics and adjustable speed drives. He has published more than 600 journal papers in the fields of power electronics and its applications. He is the co-author of four monographs and editor of ten books in power electronics and its applications.

He has received 32 IEEE Prize Paper Awards, the IEEE PELS Distinguished Service Award in 2009, the EPE-PEMC Council Award in 2010, the IEEE William E. Newell Power Electronics Award 2014, the Villum Kann Rasmussen Research Award 2014, the Global Energy Prize in 2019 and the 2020 IEEE Edison Medal. He was the Editor-in-Chief of the IEEE Transactions on Power Electronics from 2006 to 2012. He has been Distinguished Lecturer for the IEEE Power Electronics Society from 2005 to 2007 and for the IEEE Industry Applications Society from 2010 to 2011 as well as 2017 to 2018. In 2019-2020 he serves a President of IEEE Power Electronics Society. He is Vice-President of the Danish Academy of Technical Sciences too. He is nominated in 20142019 by Thomson Reuters to be between the most 250 cited researchers in Engineering in the world.

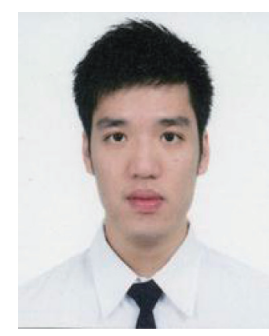

Ariya Sangwongwanich received the M.Sc. and Ph.D. degree in energy engineering from Aalborg University, Denmark, in 2015 and 2018, respectively. Currently, he is working as a Postdoc Fellow at the Department of Energy Technology, Aalborg University.

He was a Visiting Researcher with RWTH Aachen, Aachen, Germany from September to December 2017. His research interests include control of grid-connected converter, photovoltaic systems, reliability in power electronics and multilevel converters. In 2019, he received the Danish Academy of Natural Sciences' Ph.D. prize and the Spar Nord Foundation Research Award for his Ph.D. thesis. 